\title{
Reconstrução do sulco interglúteo: relato de caso
}

\author{
Intergluteal sulcus reconstruction: case report
}

Genes Lopes de Almeida

$\mathrm{JUNIOR}^{1}$

Trabalho realizado na clínica privada do autor, Brasília, DF, Brasil.

Artigo submetido pelo SGP (Sistema de Gestão de Publicações) da RBCP.

Artigo recebido: 23/7/2009 Artigo aceito: 17/9/2009

\begin{abstract}
RESUMO
Introdução: $\mathrm{O}$ conceito de beleza feminina tem mudado ao longo dos anos, porém a forma e a projeção das nádegas permanecem como símbolos de máxima feminilidade. A exposição corporal, especialmente da região glútea, tem proporcionado aumento da procura pela cirurgia de gluteoplastia. Objetivo: O propósito deste relato é demonstrar a correção cirúrgica de uma deformidade do sulco interglúteo, utilizando a preservação do ligamento sacrocutâneo. Relato do Caso: Paciente do sexo feminino, com queixa de deformidade do sulco interglúteo e nádegas hipoplásicas. $\mathrm{O}$ tratamento cirúrgico consistiu na reconstrução do sulco interglúteo por meio de preservação do ligamento sacrocutâneo, implantação de prótese de silicone glútea no plano intramuscular e lipoaspiração das ancas. Conclusão: $O$ entendimento dos princípios da técnica $\mathrm{XYZ}$, em particular do ligamento sacrocutâneo, possibilitou a correção da deformidade do sulco interglúteo e o remodelamento do contorno posterior da paciente.
\end{abstract}

Descritores: Nádegas/cirurgia. Próteses e implantes. Procedimentos Cirúrgicos Reconstrutivos/métodos.

\begin{abstract}
Introduction: The concept of female beauty has changed throught-out time, but the form and projection of the gluteal region have remained constant as symbols of maximum femininity. The body expositions, especially on the gluteal area have developed an increase of seek for buttocks surgery. Objective: The purpose of this case report is to demonstrate the importance the surgery correction of the intergluteal sulcus deformity preserving the sacral cutaneous ligament. Case Report: Female patient, with the intergluteal sulcus deformity and flat buttocks. The surgery was performed with intergluteal sulcus reconstruction, preserving the sacral cutaneous ligament, gluteal augmentation with silicone implant placed intramuscularly and hips liposuction. Conclusion: The correct comprehension of the XYZ method, especially the sacral cutaneous ligament improved the intergluteal sulcus deformity and posterior body contour of this patient.
\end{abstract}

Keywords: Buttocks/surgery. Prostheses and implants. Reconstructive Surgical Procedures/methods.

\section{INTRODUÇ̃̃O}

As nádegas têm recebido muita atenção da mídia nos últimos anos, produzindo um aumento da procura pela cirurgia de gluteoplastia. Isto se deve ao fato da melhor avaliação do contorno posterior, e das modernas técnicas de gluteoplastias ${ }^{1}$.

Morestin $^{2}$, em 1894, descreveu o sistema de suporte que mantém firme as estruturas dos tecidos moles da região glútea. Esse sistema é composto de tecido conectivo denso, que faz conexões entre a estrutura óssea ligamentar existente na parte posterior da pelve, a derme, sustentando a pele e o tecido celular subcutâneo da região glútea. O sulco interglúteo é formado por estas firmes conexões ligamentares entre a parte profunda do sacrocóccix e a derme.

Um século depois, Gonzalez ${ }^{3}$ descreveu o ligamento sacrocutâneo. Essa estrutura anatômica é uma simples expansão ligamentar dos ligamentos sacrais (parte do sistema suspensor da nádega de Morestin $^{2}$ ) e pela sua extrema resistência à tração e riqueza em tecido conectivo denso à microscopia foi denominado ligamento sacrocutâneo ${ }^{3-5}$.

1. Cirurgião Plástico; Membro Titular da Sociedade Brasileira de Cirurgia Plástica, Brasília, DF, Brasil. 
O objetivo do relato é demonstrar a importância da preservação do ligamento sacrocutâneo na reparação de uma deformidade congênita do sulco interglúteo.

\section{RELATO DO CASO}

Paciente do sexo feminino, 25 anos, pesando $57 \mathrm{~kg}$, altura de $1,62 \mathrm{~m}$ e com a circunferência da bacia medindo $97 \mathrm{~cm}$. Queixando-se de nádegas hipoplásicas, deformidade do sulco interglúteo e pequeno acúmulo de gordura na região das ancas. Paciente negava injeções no sulco interglúteo, processo infeccioso prévio ou trauma no local e relatava que a deformidade estava presente desde o nascimento (Figura 1). Ao exame físico, foi diagnosticado o sulco interglúteo desviado para

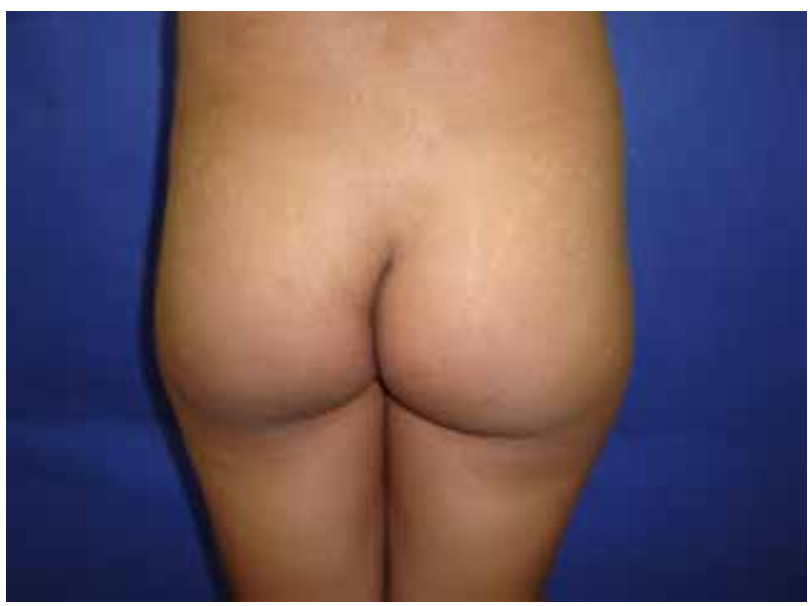

Figura 1 - Pré-operatório da deformidade congênita do sulco interglúteo.

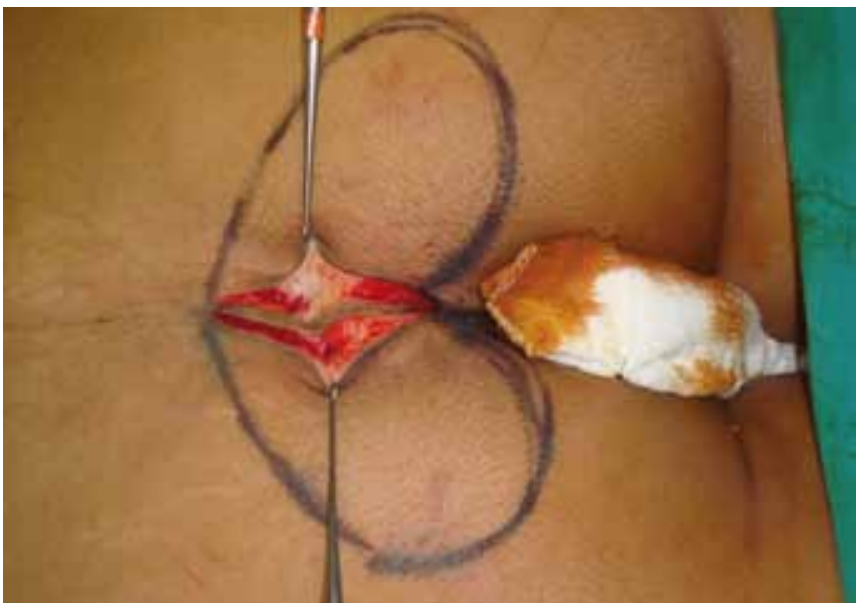

Figura 2 - Intraoperatório da preservação do ligamento sacrocutâneo. Abaixo do gancho de Gilles observa-se a retração no lado esquerdo do sulco interglúteo que foi liberada. direita, com ausência de sua profundidade no terço superior.

A cirurgia consistiu na confecção do ligamento sacrocutâneo $^{3}$ (Figura 2), liberação de uma pequena retração na porção lateral do ligamento sacrocutâneo do lado esquerdo (Figura 3), colocação de um par de implantes redondos lisos de $330 \mathrm{ml}$ no plano intramuscular utilizando a técnica $\mathrm{XYZ}^{4,5}$ e lipoaspiração das ancas.

A paciente evoluiu bem no pós-operatório e ficou satisfeita com o resultado da cirurgia (Figuras 4 a 6).

\section{DISCUSSÃO}

O conceito de beleza feminina tem mudado ao longo dos anos, porém a forma e a projeção das nádegas permanecem

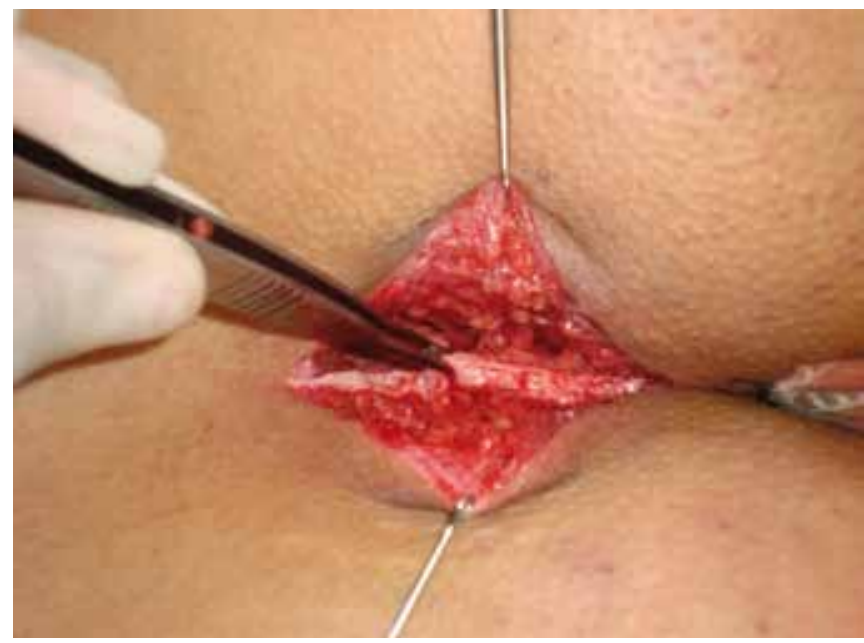

Figura 3 - Ligamento sacrocutâneo desepidermizado.

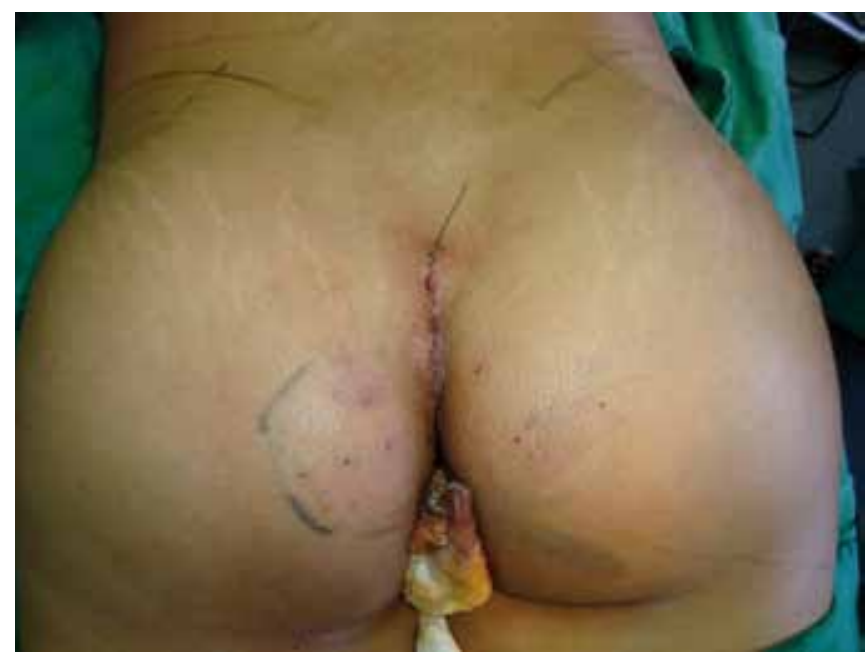

Figura 4 - Pós-operatório imediato da reconstrução do sulco interglúteo e implantação da prótese glútea intramuscular. 


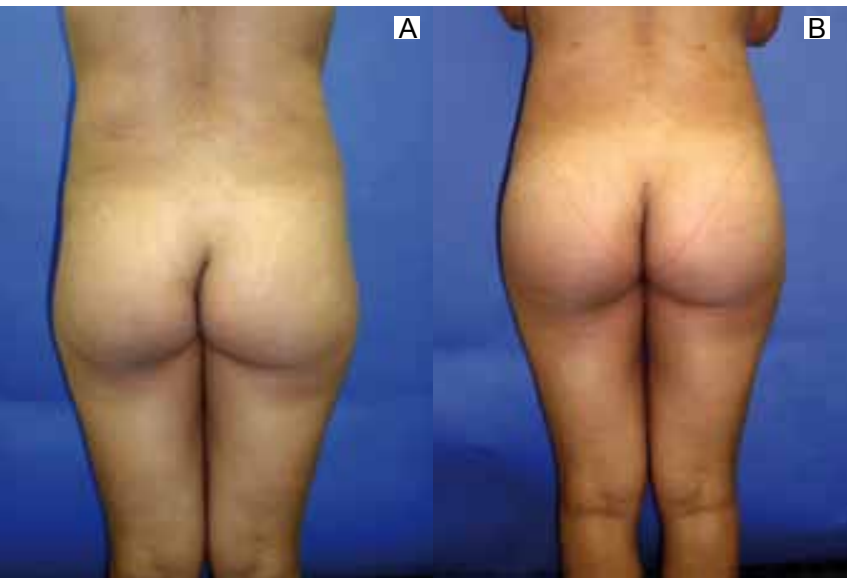

Figura 5-A: Pré-operatório. B: Pós-operatório de três meses.

como símbolos de máxima feminilidade ${ }^{1}$. Ao longo dos últimos 40 anos, vários cirurgiões plásticos desenvolveram técnicas e táticas, cujo objetivo foi proporcionar às pacientes uma forma mais sensual da região glútea ${ }^{1,3-10}$.

Neste relato, observou-se a importância do exame físico do contorno posterior da paciente, que possibilitou a correção da deformidade congênita do sulco interglúteo, lipoaspiração da região das ancas e remodelagem da nádega com a colocação de um implante de silicone intramuscular, segundo os princípios da técnica XYZ de Gonzalez ${ }^{4,5}$.

A técnica XYZ de Gonzalez ${ }^{4,5}$ contribui no sentido de estabelecer parâmetros anatômicos seguros para guiar o plano ideal de descolamento no interior do músculo glúteo máximo. A técnica possibilita a colocação das próteses em posição mais baixa, uma vez que o descolamento não é limitado pela borda superior do músculo piramidal; a preservação do ligamento sacrocutâneo; e a manutenção do sistema de fixação aponeurótico entre a pele e os tecidos profundos ${ }^{4,5,8,9}$.

Algumas técnicas cirúrgicas para introdução de prótese de silicone no espaço submuscular ${ }^{6}$, intramuscular ${ }^{7}$ e subfascial $^{8}$, através da incisão direta sobre o sulco interglúteo e a dissecção do subcutâneo, podem destruir a anatomia do sulco interglúteo.

A preservação do ligamento sacrocutâneo consiste em fazer uma incisão fusiforme, que deixa uma ilha de pele que contém em sua profundidade as expansões ligamentares sacrais que formam o sulco interglúteo. Isto fornece muitos benefícios, como: reconstituir o sulco interglúteo em caso de deformidade congênita ou adquirida do sulco; servir como referência da profundidade normal do sulco interglúteo; fornecer ancoragem para as estruturas adjacentes à incisão interglútea; separar o descolamento entre as nádegas, contribuindo no combate a

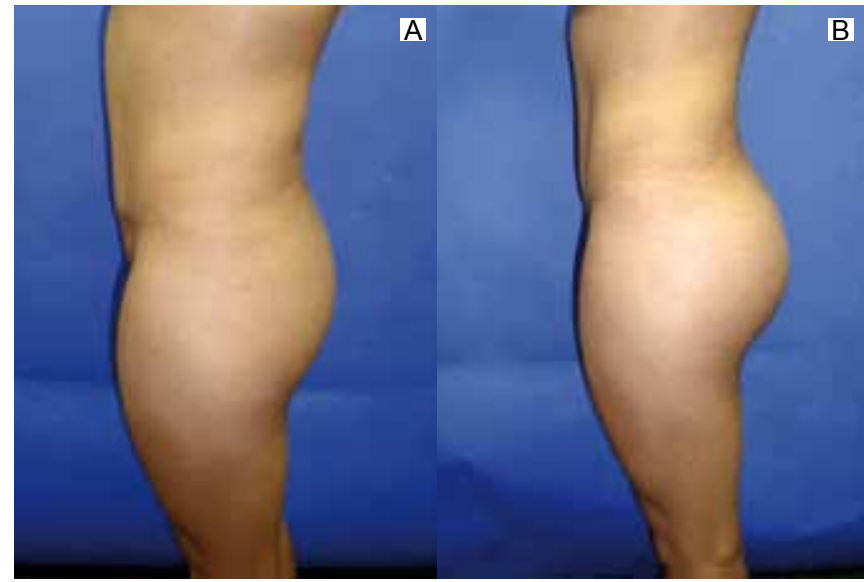

Figura 6-A: Pré-operatório. B: Pós-operatório de três meses.

infecções ou seromas que podem ocorrer no pós-operatório; otimizar o fechamento por segunda intenção no caso de deiscência e garantir a manutenção do sulco interglúteo a longo prazo, uma vez que toda a anatomia da região fica preservada ${ }^{3-5}$.

\section{CONCLUSÃO}

A preservação do ligamento sacrocutâneo é fundamental para manutenção da anatomia do sulco interglúteo, possibilitando sua reconstituição de forma segura e natural.

\section{REFERÊNCIAS}

1. Mendieta CG. Classification system for gluteal evaluation. Clin Plast Surg. 2006;33(3):333-46.

2. Morestin H. l'appareil suspenseur dupli inter-fessier in these. Paris:Bibliotéque Faculte Medicine; 1894.

3. Gonzalez R. Prótese para região glútea. In: Tournieux AAB, ed. Atualização em cirurgia plástica estética. São Paulo:Robe;1994. p.557-61.

4. Gonzalez R. Augmentation gluteoplasty: the XYZ method. Aesthetic Plast Surg. 2004;28(6):417-25.

5. Gonzalez R. Buttocks reshaping: posterior contour surgery. A step-bystep approach. Rio de Janeiro:Indexa;2006.

6. Robles JM, Tagliapietra JL, Grandi MA. Gluteoplastia de aumento: implante submuscular. Cir Plast Iberolatinoam. 1984;X:4-9.

7. Vergara R, Marcos M. Intramuscular gluteal implants. Aesthetic Plast Surg. 1996;20(3):259-62.

8. De la Penã JA, Rubio OV, Cano JP, Cedillo MC, Garcés MT. Subfascial gluteal augmentation. Clin Plast Surg. 2006;33(3):455-22.

9. Almeida Júnior GL, Almeida EG. Implante glúteo - técnica XYZ: estudo retrospectivo. Rev Bras Cir Plást. 2008;23(2):103-11.

10. Almeida Júnior GL, Castro WC, Almeida EG. Implante glúteo e posição intramuscular parcial: relato de caso. Rev Bras Cir Plást. 2009;24(2):242-5.
Correspondência para: 